\title{
Height Shift in the Radar Echoes from the $E$-Region Around the Morning and Evening Reversals
}

\author{
P. Muralikrishna and S. Prakash
}

Physical Research Laboratory, Ahmedabad, India

(Received November 9, 1976; Revised October 20, 1977)

A VHF back scatter radar installed at Thumba (dip. lat. $0^{\circ} 47^{\prime} \mathrm{S}$ ), India was used to study the nature of radar echoes close to the morning and evening electrojet reversal periods. A significant height shift in the radar echo peak was observed close to the reversals. The height region corresponding to the echo peak is seen to be higher in altitude close to the reversal periods, than before or after the reversal periods, both during mornings and evenings.

The operating frequency of the Thumba radar is $54.95 \mathrm{MHz}$. During the period of studies reported here, the pulse width of the radar was $100 \mu \mathrm{sec}$, the pulse repetition frequency 500 per sec. and the peak power of transmitter about $12 \mathrm{~kW}$. Identical dipole antenna arrays were used for transmission and reception. They had estimated gains of about $25 \mathrm{db}$. The beam widths were about $30^{\circ}$ in the $H$-plane, and $2.5^{\circ}$ in the $E$-plane. The dipole elements were aligned in the north-south direction. Though these arrays could be operated in both vertical and oblique beam modes, the results presented here are for verticalbeam-mode of operation. Further details of the Thumba Radar are given in JAIN et al. (1973), and MURALIKRIShNA (1975).

The variation of the radar echo profile with time as observed prior to the evening reversal on 14 Nov. 1974, is shown in Fig. 1. In these photographs of the scope displays, the $x$-axis represents the time delay of the radar echo peak from the leading edge of the transmitted pulse and the $y$-axis represents the echo amplitude. Variation of the time delay as the reversal period is approached is also shown in the figure. The accuracy to which the position of the echo peak can be located is about $\pm 10 \mu \mathrm{s}$. As can be seen from the figure, the time delay of the echo peak increases from a value of about $760 \mu \mathrm{s}$ at $1610 \mathrm{hrs}$ to a value of about $810 \mu \mathrm{s}$ at $1830 \mathrm{hrs}$. This corresponds to a height shift of about $7.5 \mathrm{kms}$.

In order to examine the regularity of this phenomenon of height shift, radar observations were made on a number of days. Echoes were observed more frequently during the post-morning and the pre-evening reversal periods than during the pre-morning and the post-evening reversal periods. The average features of these observations are presented in Figs. 2 and 3. The $x$-axis re- 
presents the time of observation, and the $y$-axis, the height shift in $\mathrm{kms}$. The zero along the $y$-axis is arbitrarily chosen. The morning pre-reversal curve shown in Fig. 2 is based on 8 days' observation while the one for the postreversal period is based on 12 days' observations. The average height variation

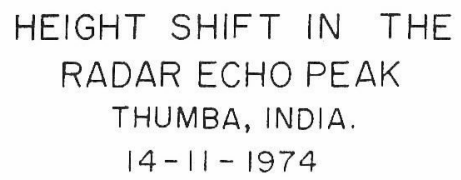

(a)
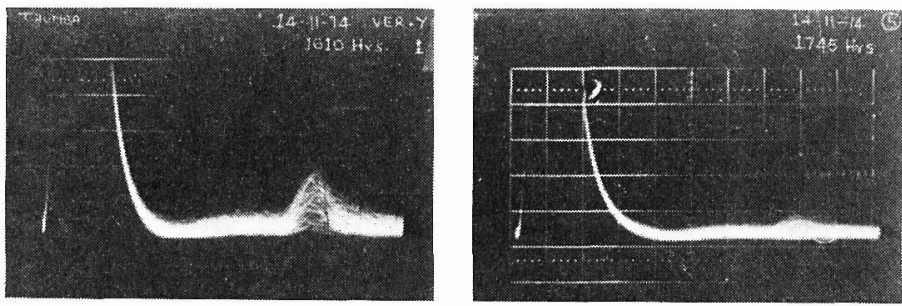

(b)
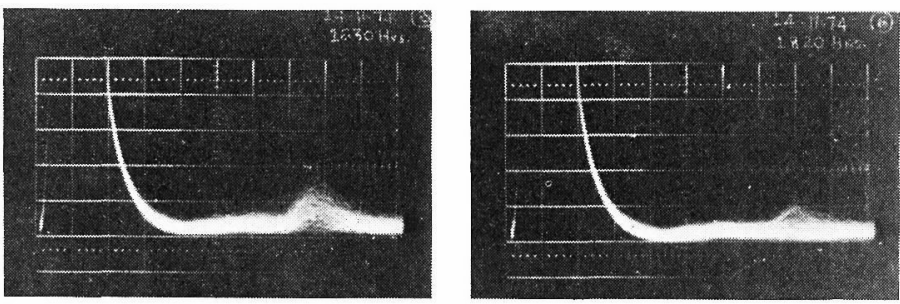

(e)

(c)
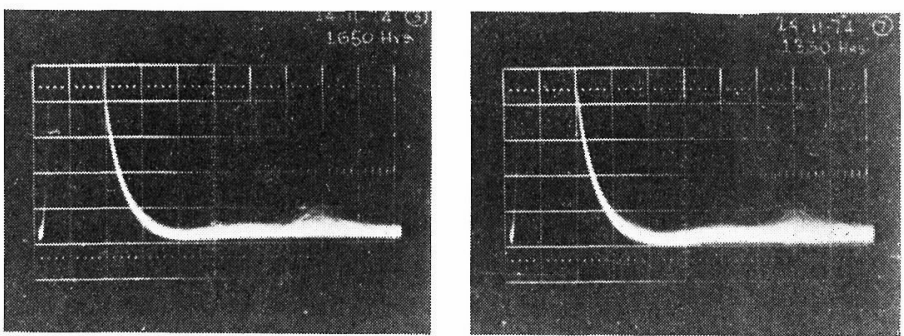

\begin{tabular}{|c|c|c|c|c|c|}
\hline TIME (IST) & $\begin{array}{l}(a) \\
1610\end{array}$ & $\begin{array}{l}\text { (b) } \\
1630\end{array}$ & $\begin{array}{l}\text { (C) } \\
1650\end{array}$ & $\begin{array}{c}\text { (d) } \\
1745\end{array}$ & $\begin{array}{l}\text { (e) } \\
1820\end{array}$ \\
\hline $\begin{array}{l}\text { ECHO PEAK } \\
\text { SOSITION } \\
\pm 10 \mu \mathrm{S})\end{array}$ & 760 & 770 & 780 & 800 & 800 \\
\hline
\end{tabular}

Fig. 1. Time variation in the radar echo profile, on 14 Nov. 1974; during the evening hours. A significant height shift can be observed as the reversal period is approached. The approximate time delays of the echo peaks from an arbitrary reference point, are also given in the figure. 
shown in Fig. 3 for the period prior to the evening reversal is based on 10 days' observation and for the period after the reversal, on 6 days' observation. On some days the observed height shift was as high as 6 to $8 \mathrm{~km}$ while on some other days it was less than the observable limit of $1.5 \mathrm{~km}$. The vertical bars in the figures represent the height ranges in which all the individual observations lie, and not the statistical error associated with the average values shown by the heavy dots in the figures. A significant upward height shift in the radar echo peak close to both morning and evening reversals of the electrojet can be clearly seen in Figs. 2 and 3.

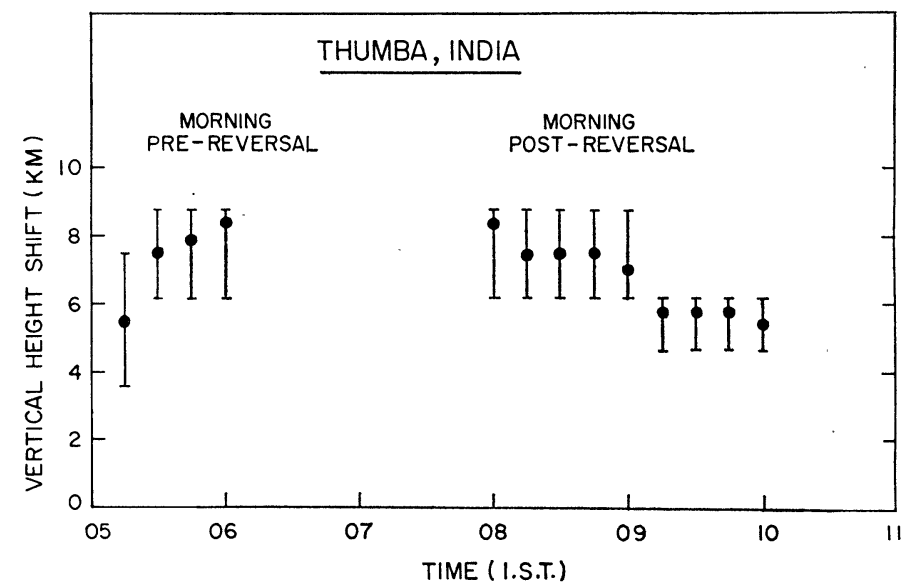

Fig. 2. Average variation with time, in the altitude of the radar echo peak, during morning electrojet reversal period. The zero of the ordinate is arbitrarily chosen.

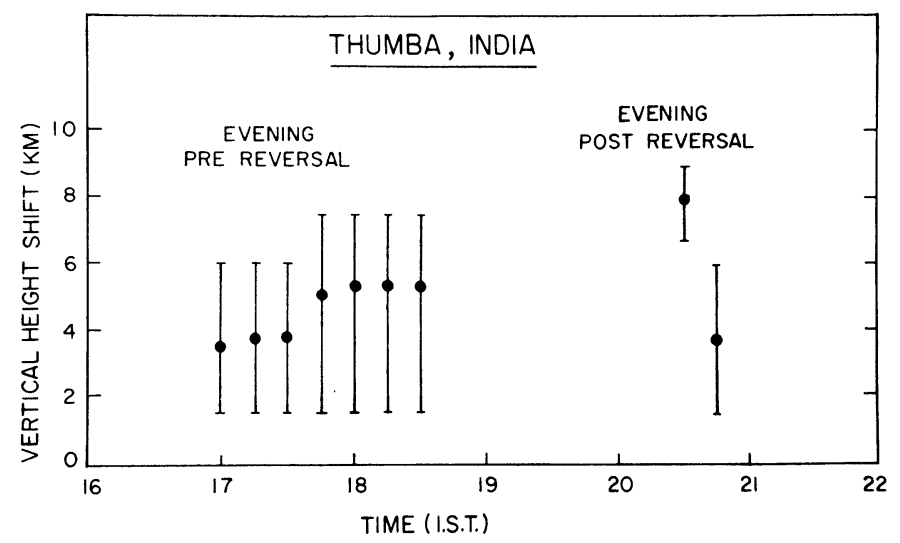

Fig. 3. Average variation with time, in the altitude of the radar echo peak, during the evening electrojet reversal period. The zero of the ordinate is arbitrarily chosen. 
From the backscatter radar studies at Jicamarca and Thumba, the electron density irregularities in the equatorial electrojet with scale sizes of about 3 meters can be classified into type I and type II (BAlsley, 1967; PraKash et al., 1974). During the present experiment, while the irregularities observed during the morning pre-reversal period were predominantly type I, they were predominantly type II during the evening pre and post reversal periods and the morning post reversal periods (Prakash and Muralikrishna, 1976). Type I irregularities are believed to be generated through the two stream instability mechanism (FARLEY, 1963) which operates when the streaming velocity of electrons exceeds a critical value, while type II irregularities, through the cross field instability mechanism (PraKash et al. 1971a, b, 1972, 1973; Fejer et al., 1975). In the altitude range of $90-115 \mathrm{kms}$, the Hall conductivity per electron calculated using CIRA 1965 model was found to vary only slightly (less than 4\%). The streaming velocity of electrons can therefore be taken to be proportional to the Hall polarization field. This indicates that the height shift in the radar echoes from Type I and Type II irregularities, is either due to a shift in the vertical profile of the Hall polarization field or in the electron density gradients. Rocket borne studies of the electron density profile at Thumba have shown that the electron density structures during morning, evening and night hours responsible for appreciable electron density gradients, range from few kms to few tens of kms (PrAKash et al., 1970; Sinha, 1976). The averaging of the radar signal over $15 \mathrm{kms}$ (as in the present case) will reduce the contribution of the electron density structures with scale sizes less than $15 \mathrm{kms}$, to the height shift of the radar echoes. The contribution to the height shift in the radar echoes due to a height shift in the Hall polarization field will not be greatly affected by this averaging over $15 \mathrm{kms}$ as the half width of the electrojet over Thumba is about $13 \mathrm{kms}$ (SАMPATH, 1976). The backscatter radar at Jicamarca has much higher resolution $(\simeq 1.5 \mathrm{~km})$ and the RTI diagrams (FEJER et al., 1975) show many distinct echo peaks. These echo peaks are believed to be due to the generation of type II irregularities in the electron density structures with scale sizes of few $\mathrm{kms}$ or more. Due to the large number of echo peaks observed in these RTI records, our data cannot be directly compared with it. As the phase relation between the radar echoes from different altitudes is not known a simple averaging of the echo strength may not be proper. The above results at Thumba can be compared with the backscatter radar at Jicamarca if a gate pulse of about $10 \mu \mathrm{sec}$ is used in the receiver.

The authors are thankful to the staff of the Back Scatter Project at VSSC, Trivandrum, India for their co-operation in making the observations presented in this report. 


\section{REFERENCES}

BALSLEy, B.B., Evidence for plasma turbulence in the equatorial electrojet, Inst. Environ. Res. Tech. Memorandum ITSA 89, 1967.

FARLEY, D.T., A plasma instability resulting in field-aligned irregularities in the ionosphere, $J$. Geophys. Res., 68, 6083-6097, 1963.

FeJer, B.G., D.T. FARLEY, B.B. BalsLey, and R.F. Woodman, Vertical structure of the V.H.F back scattering region in the equatorial electrojet and the gradient drift instability, J. Geophys. Res., 80, 1313-1324, 1975.

Jain, C.L., K.V. JANARdhanan, and P. Muralikrishna, Design of the backscatter radar system at Thumba, India, J. Rad. Space Phys., 2, 76-80, 1973.

Muralikrishna, P., Studies in equatorial aeronomy-Morphology of the electrojet, Ph.D. Thesis, Gujarat University, India, 1975.

Prakash, S., S.P. Gupta, and B.H. Subbaraya, A study of the irregularities in the night time equatorial $E$-region of the irregularities using a Langmuir probe and a plasma noise probe, Planet. Space. Sci., 18, 1307-1318, 1970.

Prakash, S., S.P. Gupta, and B.H. Subbaraya, Cross-field instability and ionisation irregularities in the equatorial $E$-region, Nature, 230, 170-171, 1971a.

Prakash, S., S.P. GUPta, and B.H. Subbaraya, Experimental evidence for cross-field instability in the equatorial ionosphere, in Space Res. XI-Akademie-Verlag, 1139-1145, Berlin, 1971b.

Prakash, S., B.H. Subbaraya, and S.P. Gupta, Rocket measurements of ionisation irregularities in the equatorial ionosphere at Thumba and identification of Plasma irregularities, Ind. J. Rad. Space Phys., 1, 72-80, 1972.

Prakash, S., S.P. Gupta, B.H. Subbaraya, H.S.S. Sinha, and C.L. Jain, A review of in situ measurements of $E$-region irregularities, Paper presented at the First Lloyd V Berkner Symp., Agu., Univ. of Texas at Dallas, Dallas, 1973.

Prakash, S., C.L. Jain, B.B. Balsley, and R.A. Greenwald, Evidence of two types of electron density irregularities in the electrojet over Thumba, India, J. Geophys. Res., 79, 43344336, 1974.

Prakash, S. and P. Muralikrishna, The nature of electric field in $E$-region close to morning and evening reversals, Geophys. Res. Lett., 3, 445-447, 1976.

Sampath, S., A study of the equatorial electrojet, Ph.D. Thesis, Gujarat University, India, 1976.

SinHA, H.S.S., Studies in equatorial aeronomy, Ph.D. Thesis, Gujarat University, India, 1976. 